\title{
Does intravenous salbutamol therapy cause cardiac toxicity in children with acute severe asthma?
}

\author{
*P K G Gunathilaka ${ }^{1}$, P M G Punchihewa ${ }^{2}$, N C Kitulwatte ${ }^{3}$, T J Athukorala ${ }^{4}$, I Kankananarachchi ${ }^{5}$, C M \\ P Fernando ${ }^{5}$, M A A Athugalpura ${ }^{6}$
}

Sri Lanka Journal of Child Health, 2016; 45(4): 250-255

\begin{abstract}
Introduction: Acute asthma is commonly treated with beta agonist therapy in the form of inhaled salbutamol. Clinicians are reluctant to use intravenous (IV) salbutamol in acute management due to the possibility of tachyarrhythmia.
\end{abstract}

Objective: To describe the effects of IV salbutamol on the heart rate and to describe any cardiac rhythm abnormalities or cardiac toxicity (ischaemia) associated with IV salbutamol therapy.

Method: A prospective, descriptive, observational study was conducted at the Medical Intensive Care Unit (MICU) Lady Ridgeway Hospital (LRH), Colombo on all children admitted with acute severe asthma from August to December 2015 who required IV salbutamol therapy. Data were collected using a self-administered questionnaire. The Wilcoxon significant rank test was utilized in statistical analysis.

Results: During the study period 30 patients were admitted to the MICU for continuous IV salbutamol therapy. The mean heart rate on admission was $197.67 \pm 15.61$. An $18 \%$ reduction (197.67 to 161.53 , $\mathrm{p}=0.000 ; \mathrm{p}<0.001)$ of heart rate was observed after introduction of IV salbutamol. Mean heart rate at the end of 12 hours of IV salbutamol was $113.20 \pm 9.05$ $(p=0.000 ; p<0.001)$. Neither cardiac arrhythmias nor elevated Troponin levels were observed in any of the patients. There was no significant hypokalaemia noted, the lowest serum potassium being $3.2 \mathrm{meq} / \mathrm{L}$.

\footnotetext{
${ }^{1}$ Senior Registrar in Paediatric Pulmonology, ${ }^{2}$ Consultant Paediatrician, ${ }^{3}$ Consultant Paediatric Intensivist, ${ }^{4}$ Senior House Officer, ${ }^{5}$ Registrar in Paediatrics, ${ }^{6}$ Senior Registrar in Paediatrics, Lady Ridgeway Hospital for Children, Colombo, Sri Lanka,

*Correspondence: gunathilakapkg@gmail.com
}

(Received on 06 December 2015: Accepted after revision on 21 January 2016)

The authors declare that there are no conflicts of interest.

Personal funding was used for the project.

Open Access Article published under the Creative Commons Attribution CC-BY cc) (ب) License.
Conclusions: IV salbutamol did not increase the heart rate but caused a reduction in tachycardia. Whilst sinus tachycardia was observed in all patients, there were no cardiac rhythm abnormalities and no cardiac toxicity.

DOI: http://dx.doi.org/10.4038/sljch.v45i4.8055

(Key words: Acute severe asthma, intravenous salbutamol, heart rate, Troponin I, arrhythmias)

\section{Introduction}

Airway obstruction is the result of contraction of the smooth muscle and oedema of the airway due to smooth muscle hypertrophy and hyperplasia, inflammatory cell infiltration, goblet cell and mucous gland hyperplasia, mucous hypersecretion, protein deposition including collagen, and epithelial desquamation $^{1,2}$. Relatively high doses of beta 2 receptor agonists are routinely used for hours to days in hospitalized children ${ }^{3,4}$. For rapid bronchodilatation, penetration of inhaled drug to the affected small conducting airways may be impeded, and consequently responses may be a result of drug reaching the receptors via the systemic circulation ${ }^{3}$. Browne $\mathrm{G} J$ et al carried out a randomized, doubleblind, placebo-controlled trial of intravenous (IV) salbutamol and nebulized ipratropium bromide in early management of severe acute asthma in children presenting to an emergency department ${ }^{5}$. In this study children administered IV salbutamol showed a more rapid recovery time, which resulted in earlier discharge from the hospital than those administered inhaled ipratropium bromide. IV salbutamol therapy is recommended in the management of acute severe asthma ${ }^{2}$. However, clinicians seem to be reluctant to use IV salbutamol in acute management due to fear of tachyarrhythmia. Thus we thought it important to conduct a study on IV salbutamol therapy in children with acute severe asthma.

Objectives

1. To describe the effects of IV salbutamol on heart rate.

2. To describe the cardiac rhythm abnormalities, if any, associated with IV salbutamol therapy. 
Does intravenous salbutamol therapy cause cardiac ...Sri Lanka Journal of Child Health, 2016; 45(4): 250-255

3. To describe whether IV salbutamol therapy is associated with cardiac toxicity (ischaemia).

\begin{abstract}
Method
A prospective, descriptive observational study was conducted at the Medical Intensive Care Unit (MICU) at Lady Ridgeway Hospital (LRH) for Children. Out of admissions to MICU with acute severe asthma between August 2015 and December 2015 , all children with acute severe asthma who required IV salbutamol therapy were included in the study. None were excluded. The study was approved by the Ethical Review Committee, Lady Ridgeway Hospital, Colombo. Informed written consent was obtained from parents or the guardian of each patient.
\end{abstract}

Demographic, historical and clinical data were collected using a data extraction sheet. Data were extracted from the monitoring chart and included patient's age, gender, race / ethnicity and asthma history. Data were also extracted regarding the hospital course, treatments received and the durations of these therapies.

At MICU, LRH, patients with acute severe asthma were managed according to the unit protocol. It was principally based on the British Thoracic Society guidelines ${ }^{6}$. After admission to MICU patients were administered with oxygen via face mask $(6 \mathrm{~L} / \mathrm{min})$ or via a non-rebreathing bag $(10-15 \mathrm{~L} / \mathrm{min})$. They were started on nebulization with salbutamol in the initial period. IV salbutamol was started in patients with a poor response to initial management. IV salbutamol was started at a rate of $1 \mu \mathrm{g} / \mathrm{kg} / \mathrm{min}$ and the dosage was subsequently increased by $1 \mu \mathrm{g} / \mathrm{kg} / \mathrm{min}$ at 15 to 30 minute intervals. The maximum rate of IV salbutamol used was $10 \mu \mathrm{g} / \mathrm{kg} / \mathrm{min}$. All the children were connected to a continuous cardiac monitor with pulse rate, respiratory rate, pulse oximetry and electrocardiogram (ECG) (lead II and V). A 12 lead ECG was used whenever a rhythm abnormality was displayed on the monitor and 12 hours after discontinuation of IV salbutamol therapy.
Furthermore, observations were made on the variations of heart and respiratory rate every 15 minutes. Serum potassium was monitored prior to IV salbutamol and at intervals of 4 hours. Serum potassium was maintained within the normal range $(3.5 \mathrm{mmol} / \mathrm{L}-5 \mathrm{mmol} / \mathrm{L})$ with the use of continuous infusions of IV potassium chloride and rapid corrections made whenever necessary. Serum troponin I levels were done prior to and during the maximum salbutamol infusion to look for cardiac ischaemia. For troponin-I, a level of $>0.03 \mathrm{ng} / \mathrm{mL}$ was considered elevated. Serum lactate levels were not done due to lack of facilities.

Data were analysed using SPSS statistical software (version 16). The data were reported as frequencies $(\%)$, as mean \pm standard deviation or as median with $25 \%-75 \%$ interquartile range (IQR) depending on the type and distribution of the variables. Data were analysed using Wilcoxon Signed Rank test. P values of $<0.05$ were considered statistically significant.

\section{Results}

During the study period 30 patients were admitted to the MICU for continuous IV salbutamol therapy. The median age was 5.5 years with 2.25 IQR $(\mathrm{Q} 1=4.75$, $\mathrm{Q} 4=7.00)$. Of the 30 children, 56\% were female, $53 \%$ had previously been admitted to hospital with an exacerbation of asthma and one child had previously been admitted to an ICU with asthma. All the children received continuous IV salbutamol therapy of at least $5 \mu \mathrm{g} / \mathrm{kg} / \mathrm{min}$ for at least 12 hours' duration. Median duration of the continuous IV salbutamol therapy was 36 hours. Eight $(26 \%)$ of these 30 patients were also treated with continuous IV magnesium sulphate. None of these children required mechanical ventilation.

The mean respiratory rate on admission to the MICU was $80 /$ minute and rose to $84 /$ minute at the commencement of IV salbutamol. In all cases there was a decline of respiratory rate (mean 29.9) with the increment of IV salbutamol (Figure 1) 


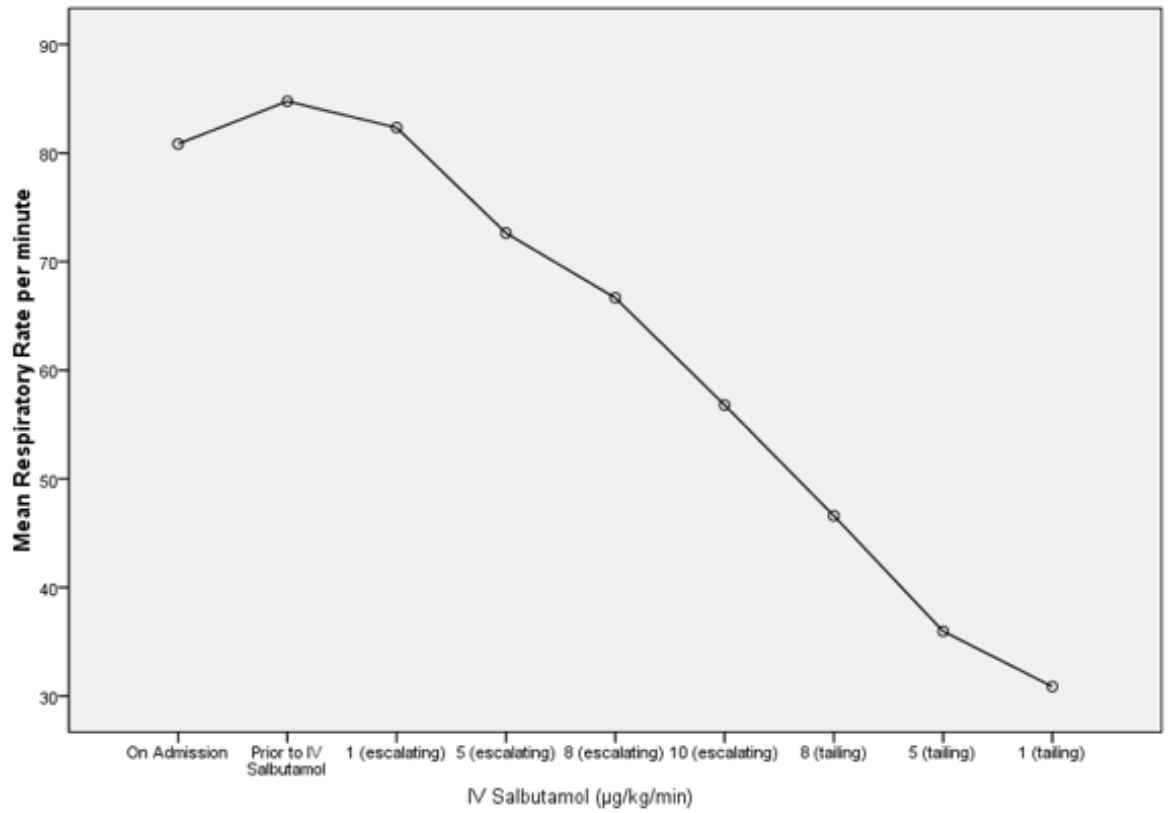

Figure 1: Changes of respiratory rate on intravenous salbutamol therapy

The mean heart rate per minute on admission was $193.20 \pm 19.39$ and this went up to $197.67 \pm 15.61$ at the beginning of IV salbutamol. An $18 \%$ reduction (197.67 to $161.53, \mathrm{p}=0.000 ; \mathrm{p}<0.001)$ of heart rate was observed with introduction of IV salbutamol.
However, the heart rate remained at the same level until discontinuation of IV salbutamol. Mean heart rate at the end of 12 hours of IV salbutamol was 113.2 \pm 9.05 (Figure 2).

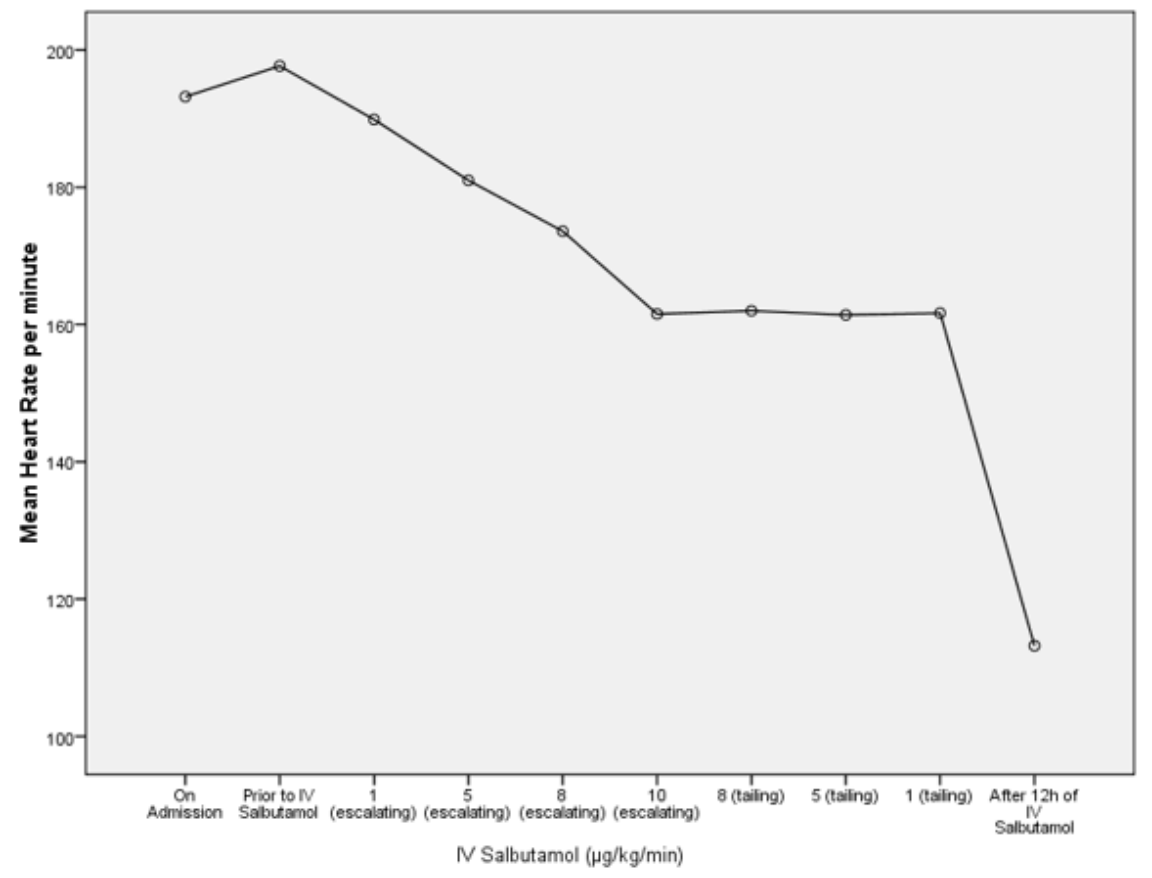

Figure 2: Changes of heart rate on intravenous salbutamol therapy

None of these patients had ECG changes of cardiac arrhythmia or ischaemic changes, whereas sinus tachycardia was observed in all patients. Troponin I levels which were done after 08 hours of discontinuation of IV salbutamol were within normal limits in all patients. None of these patients required discontinuation of medication due to significant cardiac toxicity. Three $(10 \%)$ out of thirty subjects had low serum potassium levels (lowest 3.2) during the therapy (Figure 3). 


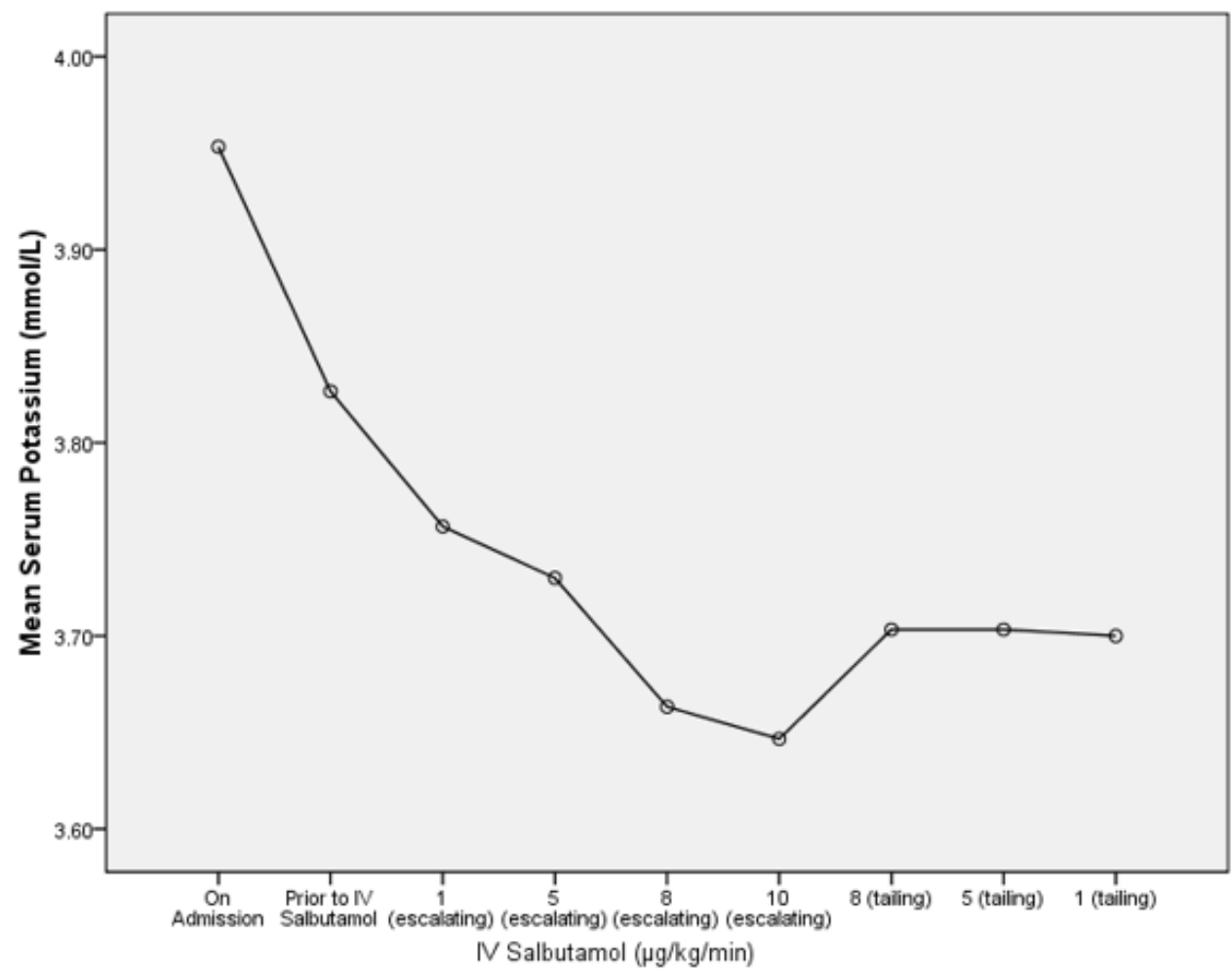

Figure 3: Changes of serum potassium on intravenous salbutamol therapy

Using the Wilcoxon Signed Rank test we compared the respiratory rate, heart rate and serum potassium with the relevant values on admission and different
IV salbutamol doses. The relevant $\mathrm{p}$ values are shown in tables 1 to 3 .

Table 1: Comparison of respiratory rates in different stages of IV salbutamol infusions

\begin{tabular}{|l|c|c|}
\hline \multicolumn{1}{|c|}{ Respiratory rate per minute } & Median difference & p value \\
\hline Prior to starting IV salbutamol and on admission to MICU & $(84.77-80.83)$ & 0.005 \\
\hline Tailing off of IV salbutamol $(1 \mu \mathrm{g} / \mathrm{kg} / \mathrm{min})$ and on admission to MICU & $(30.87-80.83)$ & 0.000 \\
\hline Tailing off of IV salbutamol $(1 \mu \mathrm{g} / \mathrm{kg} / \mathrm{min})$ and prior to starting IV salbutamol & $(30.87-84.77)$ & 0.000 \\
\hline
\end{tabular}

Table 2: Comparison of heart rates in different stages of IV salbutamol infusions

\begin{tabular}{|l|c|c|}
\hline \multicolumn{1}{|c|}{ Heart rate per minute } & Median difference & p value \\
\hline Prior to starting IV salbutamol and on admission to MICU & $(197.67-193.20)$ & 0.165 \\
\hline IV salbutamol (escalating) $10 \mu \mathrm{g} / \mathrm{kg} / \mathrm{min}$ and on admission to MICU & $(161.53-193.20)$ & 0.000 \\
\hline IV salbutamol (escalating) $10 \mu \mathrm{g} / \mathrm{kg} / \mathrm{min}$ and prior to starting IV salbutamol & $(161.53-197.67)$ & 0.000 \\
\hline IV salbutamol (tailing) $1 \mu \mathrm{g} / \mathrm{kg} / \mathrm{min}$ and IV salbutamol (escalating) $10 \mu \mathrm{g} / \mathrm{kg} / \mathrm{min}$ & $(161.67-161.53)$ & 0.578 \\
\hline After $12 \mathrm{~h}$ of IV salbutamol infusion and IV salbutamol (tailing) $1 \mu \mathrm{g} / \mathrm{kg} / \mathrm{min}$ & $(113.20-161.67)$ & 0.000 \\
\hline
\end{tabular}

Table 3: Comparison of serum potassium levels in different stages of IV salbutamol infusions

\begin{tabular}{|l|c|c|}
\hline \multicolumn{1}{|c|}{ Serum potassium (mmol/L) } & Median difference & p value \\
\hline Prior to starting IV salbutamol and on admission to MICU & $(3.83-3.95)$ & 0.016 \\
\hline IV salbutamol (escalating) $10 \mu \mathrm{g} / \mathrm{kg} / \mathrm{min}$ and on admission to MICU & $(3.65-3.95)$ & 0.000 \\
\hline IV salbutamol (escalating) $10 \mu \mathrm{g} / \mathrm{kg} / \mathrm{min}$ and prior start to IV salbutamol & $(3.65-3.83)$ & 0.000 \\
\hline IV salbutamol (tailing) $1 \mu \mathrm{g} / \mathrm{kg} / \mathrm{min}$ and on admission to MICU & $(3.70-3.95)$ & 0.000 \\
\hline IV salbutamol (tailing) $1 \mu \mathrm{g} / \mathrm{kg} / \mathrm{min}$ and prior to starting IV salbutamol & $(3.70-3.83)$ & 0.014 \\
\hline
\end{tabular}


Does intravenous salbutamol therapy cause cardiac ... Sri Lanka Journal of Child Health, 2016; 45(4): 250-255

\section{Discussion}

Chiang VW et al. carried out a prospective cohort study of children receiving IV terbutaline for severe asthma ${ }^{7}$. In this study only $3(10 \%)$ of the 29 patients had elevations in serum cardiac troponin T. Bogie $\mathrm{AL}$ et al carried out a comparison of IV terbutaline versus normal saline in paediatric patients on continuous high-dose nebulized albuterol for status asthmaticus 8 . In this study one child in the terbutaline group was removed from the study for a significant cardiac dysrhythmia ${ }^{8}$. Carroll CL et al conducted a retrospective review of children admitted to the ICU between May 2008 and April 2009, who were treated with continuous betaagonist therapy (IV and nebulized) ${ }^{9}$. In this review, elevated troponin-T levels were found in $25 \%$ of children. However, all returned to normal levels within 48 hours of ICU admission, despite continued beta-agonist therapy ${ }^{9}$. No children experienced arrhythmias during therapy and there was no association between IV terbutaline use and elevated troponin- $\mathrm{T}$ [odds ratio (OR), $1.3 ; 95 \% \mathrm{CI}, 0.2-$ $10.3]^{9}$. In our small cohort of 30 critically ill children with acute severe asthma, all children had transient sinus tachycardia but none of them had cardiac arrhythmias or cardiac toxicity.

One of the salient pathological feature of acute severe asthma is bronchoconstriction which leads to hypoxia and tachypnoea. Severe bronchoconstriction in acute severe asthma prevents inhaled salbutamol reaching the target receptors where IV salbutamol could alleviate this phenomenon. This in turn results in reduction in respiratory rate as seen in our study. Thus this could be used as a marker of therapeutic response ${ }^{9,10}$. In acute severe asthma, tachycardia occurs as a response to hypoxia as well as a relative reduction of effective cardiac output due air trapping resulting in increased intrathoracic pressure. Rising of the heart rate before commencing IV salbutamol was due to disease progression. Reduction of heart rate after commencing salbutamol is the therapeutic response while the persistence of tachycardia thereafter is due to the beta-1 effects of salbutamol. This phenomenon is further supported by gradual normalization of heart rate following discontinuation of IV salbutamol. A similar observation has been reported by Aldington $\mathrm{S}$ et al in 2007 in an adult study ${ }^{11}$. Thus, salbutamol therapy should be commenced despite the tachycardia because salbutamol through its action on beta 2 receptors relieves hypoxia and improves venous return and cardiac output which will reduce the heart rate up to a certain extent. In our cohort, none of the children had an elevation in their serum troponin-I levels. Serum potassium levels were maintained within the normal range during IV salbutamol therapy due to additional potassium supplementation.

Our study had some limitations. The sample size was small and reflected only a subset of the larger cohort admitted with acute asthma. Therefore, generalizing these results have to be done cautiously. Serum lactate levels were not measured due to limited facilities.

\section{Conclusions}

1. IV salbutamol did not increase the heart rate but caused a reduction in tachycardia.

2. Whilst sinus tachycardia was observed in all patients, there were no cardiac rhythm abnormalities and no cardiac toxicity.

\section{Acknowledgements}

Our sincere gratitude to Mr K A C D Kumbalatera (Data Analytic Consultant, Shared Knowledge Solutions Asia Pacific) for the statistical analysis in this project.

\section{References}

1. Sellers WFS. Inhaled and intravenous treatment in acute severe and lifethreatening asthma. British Journal of Anaesthesia 2013; 110(2): 183-90.

http://dx.doi.org/10.1093/bja/aes444

PMid: 23234642

2. British guideline on the management of asthma October 2014. Available from: https://www.britthoracic.org.uk/document-library/clinicalinformation/asthma/btssign-asthmaguideline-2014/

3. Andrew A, Travers, Arthur PJ, Karen DK, Carlos AJC, Brian HR. Intravenous beta2agonists for acute asthma in the emergency department. The Cochrane Collaboration 2012. Available from:

http://www.cochranelibrary.com/

4. Suzanne S, Patricia P, Aziza R, Gerald C. High-versus low-dose, frequently administered, nebulized albuterol in children with severe, acute asthma. Pediatrics 1989; 83(4):513 -8.

5. Browne GJ, Penna AS, Phung X, Soo M. Randomised trial of intravenous salbutamol in early management of acute 
severe asthma in children. Lancet 1997; 349(9048):301-5.

http://dx.doi.org/10.1016/S01406736(96)0 6358-1

6. British Thoracic Society Asthma Guidelines. Available from: https://www.britthoracic.org.uk/guidelines-and-qualitystandards/asthma-guideline/

7. Chiang VW, Burns JP, Rifai N, Lipshultz SE, Adams MJ, Weiner DL. Cardiac toxicity of intravenous terbutaline for the treatment of severe asthma in children: a prospective assessment. Journal of Pediatrics 2000; 137:73-7.

http://dx.doi.org/10.1067/mpd.2000.10656 7

PMid: 10891825

8. Bogie AL, Towne D, Luckett PM, Abramo TJ, Wiebe RA. Comparison of intravenous terbutaline versus normal saline in paediatric patients on continuous high-dose nebulized albuterol for status asthmaticus. Pediatric Emergency Care 2007; 23:35561.

http://dx.doi.org/10.1097/01.pec.0000278

397.63246 .33

PMid: 17572517
9. Carroll CL, Coro M, Cowl A, Sala KA, Schramm CM. Transient occult cardiotoxicity in children receiving continuous beta-agonist therapy. World Journal of Pediatrics 2014; 10(4):324-9. http://dx.doi.org/10.1007/s12519-0140467-z

PMid: 24599614

10. Bohn D, Kalloghlian A, Jenkins J, Edmonds JF, Barker G. Intravenous salbutamol in the treatment of status asthmaticus in children. Critical Care Medicine 1984; 12(10):892-6.

http://dx.doi.org/10.1097/0000324619841 0000-00012

PMid: 6435957

11. Aldington S, Beasley R. Asthma exacerbations - 5: Assessment and management of severe asthma in adults in hospital. Thorax 2007; 62(5): 447-58.

http://dx.doi.org/10.1136/thx.2005.045203

PMid: 17468458 PMCid: PMC2117186 